\title{
Blood product utilisation for coronary artery bypass graft surgery at a public and a private hospital in Western Cape Province, South Africa
}

\author{
D Wolmarans, ${ }^{1,2}$ BTech (Biomed Sci); A Bird, ${ }^{2}$ MMed (Haem); C Uys, ${ }^{3}$ DTech (Informatics); G M Davison, ${ }^{1,4} \mathrm{PhD}(\mathrm{Haem})$ \\ ${ }^{1}$ Department of Biomedical Sciences, Faculty of Health and Wellness Sciences, Cape Peninsula University of Technology, Cape Town, South Africa \\ ${ }^{2}$ Western Cape Blood Service, Cape Town, South Africa \\ ${ }^{3}$ Centre for Postgraduate Studies, Cape Peninsula University of Technology, Cape Town, South Africa \\ ${ }^{4}$ SAMRC/CPUT Cardiometabolic Health Research Unit, Department of Biomedical Sciences, Faculty of Health and Wellness Sciences, \\ Cape Peninsula University of Technology, Cape Town, South Africa
}

Corresponding author: G M Davison(davisong@cput.ac.za)

\begin{abstract}
Background. Numerous studies have documented variation in transfusion practice for coronary artery bypass graft (CABG) surgery, despite the widespread availability of clinical guidelines. Blood management systems seek to streamline utilisation, with key indicators being patient care and outcome as well as reduction of waste and cost.

Objectives. To facilitate this view, this study sought to audit blood product utilisation for CABG surgery at a private and a public sector hospital in Western Cape Province, South Africa.

Methods. A retrospective audit of 100 consecutive patients undergoing CABG surgery at a private and a public hospital during 2017 was performed. Blood product use was compared between the two hospitals, and the influence of confounding factors such as gender, weight, age, pre- and intraoperative medications, type and complexity of the procedure, and patient comorbidities was analysed.

Results. The proportion of patients receiving red cell concentrates (RCCs) at the public hospital was significantly higher than at the private hospital $(92 \%$ v. $56 \%$; $p<0.001)$, which resulted in significantly higher postoperative haemoglobin concentrations $(p<0.001)$. Although the increased proportion of RCC transfusion observed at the public hospital may have been influenced by decreased body mass $(p<0.001)$, the patient population at the private hospital was older $(p<0.05)$ and had higher rates of ischaemia $(p<0.001)$, increased numbers of grafts $(p<0.001)$ and higher preoperative use of aspirin $(p<0.05)$.

Conclusions. This study demonstrated increased use of blood products at the public hospital, despite performing fewer grafts. Although this study had limitations, which included low patient numbers and the inclusion of only two hospitals, we concluded that there is a significant variation in the use of blood products despite the risks associated with blood transfusion. These findings could be used to employ systems that will lead to improved blood usage practices.
\end{abstract}

S Afr Med J 2021;111(11):1110-1115. https://doi.org/10.7196/SAMJ.2021.v111i11.15676

Although blood products are the favoured choice for replacing volume, replenishing coagulation factors and restoring tissue oxygenation, evidence suggests that the use of red cell concentrates (RCCs) in particular is often inappropriately high despite the potential risks and financial costs. ${ }^{[1,2]}$ Numerous studies have shown that patient outcome is in no way affected by whether a restrictive or liberal transfusion strategy is used. ${ }^{[3,4]}$ However, despite the availability of clinical guidelines, significant variation occurs in transfusion practice, although the underlying causes for these differences remain unclear. ${ }^{[5-7]}$

Substantial blood loss is common during coronary artery bypass graft $(\mathrm{CABG})$ surgery, causing anaemia and placing stress on the heart because of an increase in cardiac output. ${ }^{[8]}$ The most rapid approach to combat anaemia remains blood transfusion, ${ }^{[9]}$ and therefore, despite increasing awareness and improved technology, the variation in blood product use in cardiac surgery remains significant.

This wide variation has been demonstrated in many studies. For example, an audit of 82446 cardiac patients at 408 hospitals $^{[7]}$ reported that the rates of blood transfusion for cardiac surgery ranged from $7.8 \%$ to $92 \%$ for RCCs, from $0 \%$ to $97 \%$ for fresh-frozen plasma (FFP) and from $0.4 \%$ to $90.4 \%$ for platelets. These differences remained despite adjustments for risk factors. Others have demonstrated similar findings, with transfusion rates ranging from $33 \%$ to $74 \% .{ }^{[10]}$ In South Africa (SA), two studies, conducted on patients undergoing cardiac surgery at academic centres in Johannesburg and KwaZuluNatal Province, demonstrated and confirmed the high rates of blood product use in patients undergoing cardiac surgery ${ }^{[11,12]}$ Both these articles suggested the use of blood management guidelines to assist in prevention of unnecessary blood transfusion.

SA's healthcare delivery is divided into two systems, with the private sector providing medical services to those with medical aid cover and other sources of funding, while public hospitals, funded by the government, provide a service to the majority of lower-income South Africans. The level and quality of service offered by these two tiers of healthcare differ significantly. ${ }^{[13]}$ Owing to these differences, it has been hypothesised that significant variation may exist between blood usage practices of clinicians performing CABG surgery in the private sector compared with those in the public sector.

\section{Objectives}

As few studies have been conducted in Western Cape Province, the objectives of this study were to examine transfusion practices at a 
private and a public sector hospital, as well as the clinical features of the patient populations.

\section{Methods}

\section{Patient population and study design}

This was a retrospective study of 100 consecutive patients equally divided between a private hospital and a public hospital. Participants were recruited during 2017 in the Western Cape, and unscheduled patients undergoing multiple cardiac procedures including coronary angioplasty and/or stent insertion, valve replacement and pacemaker insertion were excluded from the analysis.

\section{Ethical and legal considerations}

Confidentiality was maintained by ensuring that patient and clinical staff details at each hospital were anonymised. For the purposes of the audit, unique study numbers were created for each institution. These numbers were P1 - 50 for the private hospital and T1 - 50 for the public hospital, and were linked with the data collection form. As the data collection was retrospective and anonymised, a waiver of consent was sought and granted. Ethics approval was obtained from the Cape Peninsula University of Technology's Ethics Committee (ref. no. CPUT/HW-REC2016/H32), and approval to collect the data was granted by the management of the relevant hospitals.

\section{Data collection}

A data collection form detailing the required information was devised. At the private hospital, data were collected and recorded onto the information sheet by the hospital staff, while at the public hospital, the records of 50 consecutive cardiac surgery patients were made available to the investigator, who recorded the information onto the collection form. Data were cross-checked with the Western Cape Blood Service records. All information was transcribed onto the data collection form for data capture and analysis. Transfusion episodes were recorded from the time surgery commenced and concluded at 24 hours post surgery.

The data form included information on the following patient parameters: gender, weight, age, details of preoperative anticoagulants including aspirin, clopidogrel and warfarin, and comorbidities including hypertension, diabetes mellitus, ischaemic heart disease, renal dysfunction and congestive heart failure, as well as cerebrovascular disease or stroke.

Additional information gathered included the details of the procedure itself, the number of grafts performed, whether the operation was on or off pump, and intraoperative use of the anticoagulant heparin and its reversal with protamine. Further information on any blood conservation techniques, such as the use of cell salvage equipment and antifibrinolytics such as aprotinin and tranexamic acid, was also recorded.

Information on pre- and postoperative laboratory test results was documented and included serum creatinine levels, international normalised ratio (INR) and activated partial thromboplastin time (aPTT), as well as haemoglobin $(\mathrm{Hb})$ values and platelet counts. Finally, details on the numbers and type of blood products used were recorded.

\section{Statistical analysis}

All data were transcribed onto a predesigned Excel worksheet (version 15.0.4420.1017, 2013; Microsoft, USA) with standardised input methods. The use of a double-entry method ensured capture accuracy, while data duplication was limited by the use of unique study numbers. The data were then uploaded to an SPSS version 22 statistical package (IBM, USA) for analysis. Information obtained in this way included frequency and contingency tables as well as a descriptive analysis for numerical variables using the median and the interquartile range (IQR).

Where deemed suitable, summary statistics were portrayed as medians and IQRs. Performance indicators included the number of patients transfused as well as the number of units transfused per hospital. The $\chi^{2}$ test was used to identify significant differences between two or more groups pertaining to categorical variables or to determine the significant association between two categorical variables. The independent-samples median test was used to compare the medians of counts between two groups. The independentsamples Mann-Whitney $U$-test was used to test for differences between two groups of numerical variables, and $p$-values were given to test the null hypothesis, thereby testing the validity of a claim made about a population. These $p$-values given for information purposes were compared against a significance value of $<0.05$.

\section{Multivariate analysis}

The assumption of normality, which is required for classic linear models, is violated when working with ordinal variables. The dependent variables (RCCs, FFP and platelets) are all ordinal variables. However, owing to scarcity of data, FFP and platelets were transformed to binary variables, indicating whether the blood product was given or not. The variable RCCs was also transformed to an ordinal variable with fewer categories for the same reason. Therefore, a generalised linear model of the family of linear models that includes analysis of variance as well as regression models was utilised to determine which factors or measurements influenced blood usage in the hospitals. ${ }^{[14,15]}$

The three components making up the generalised linear model are a random component, a systematic component and a link function. ${ }^{[16]}$ The assumption of normality is relaxed in the generalised linear model. The distribution of the dependent values can be from any of the class of exponential distributions. The type of data of the dependent variable informs the choice of the link function. In this study, the selected link function for the ordinal dependent variables was the cumulative logit link function, and for the binary variables it was the logit link function. The analysis, in each of the three cases, was repeated until a model that fitted the data well, as indicated by the goodness-of-fit statistics, emerged.

\section{Results}

\section{Study population}

The study population reviewed was 50 consecutive patients undergoing $\mathrm{CABG}$ surgery from each hospital. The only significant differences observed between the baseline characteristics of the patients (Table 1) were age, which was significantly higher at the private hospital $(p<0.05)$, the number of grafts performed $(p<0.001)$ and levels of ischaemia $(p<0.001)$, which were both higher at the private hospital, and body weight, which was significantly lower at the public hospital $(p<0.05)$.

\section{RCC analysis}

Seventy-four percent of the total patients received RCCs within 24 hours of the procedure: 28 of these were from the private hospital and 46 from the public hospital. The remaining patients, 22 from the private hospital and 4 from the public hospital, did not receive any RCC transfusion.

Subsequently, a significant difference in RCC transfusion rates between the private hospital and the public hospital was noted (56\% 
v. $92 \% ; \chi^{2}=16.84, \mathrm{df}=1, p<0.001$ ), as seen by the use of 166 RCC units at the public hospital compared with only 99 at the private hospital. Although there was no significant difference between preoperative $\mathrm{Hb}$ concentrations $(14.0 \mathrm{~g} / \mathrm{dL}$ at the private hospital compared with the public hospital's $13.8 \mathrm{~g} / \mathrm{dL}$ ), as shown by the independent-samples Mann-Whitney $U$-test $(p>0.05)$, the postoperative $\mathrm{Hb}$ results were significantly different $(11.2 \mathrm{~g} / \mathrm{dL}$ v. $14.1 \mathrm{~g} / \mathrm{dL} ; p<0.001)$

\section{FFP and platelets}

There was a significant difference in the use of FFP between the two hospitals (exact $\chi^{2}=13.457, \mathrm{df}=4, p<0.01$ ), with 37 units used at the public hospital compared with 4 at the private hospital. The two groups had similar median INR results (Mann-Whitney $U$-test $p>0.05)$ and aPTTs, with both falling within the normal reference range.
Pre- and postoperative platelet counts from both institutions support the relatively low use of platelets, as only 13 units of pooled platelets were used at the private hospital and 11 at the public hospital (exact $\chi^{2}=1.444, \mathrm{df}=4, p>0.05$ ). The median (IQR) preoperative platelet count at the public hospital was $263.5(111) \times 10^{9} / \mathrm{L}$ and at the private hospital $233(111) \times 10^{9} / \mathrm{L}$, while the median (IQR) postoperative platelet count at the private hospital was $189(63) \times$ $10^{9} / \mathrm{L}$ and that at the public hospital $222.5(138) \times 10^{9} / \mathrm{L}$, both well above the recommended reference range for transfusion.

\section{Variables influencing RCC use}

Before transformation to an ordinal variable, eight variables emerged as having a significant influence on blood use by the hospitals (Table 2). The most significant factor in the use of RCCs was the type of hospital $(p<0.001)$, followed by age $(p<0.01)$, number of grafts

Table 1. Demographics and baseline characteristics

\begin{tabular}{|c|c|c|c|c|}
\hline & All patients & $\mathbf{P}$ & $\mathrm{T}$ & $p$-value \\
\hline Total, $N$ & 100 & 50 & 50 & \\
\hline Age (years), median (IQR) & $61(16)$ & $63(15)$ & $57(12)$ & $<0.05^{*}$ \\
\hline Weight $(\mathrm{kg})$, median (IQR) & $82.5(29.8)$ & $86(33)$ & $78(19.5)$ & $<0.05^{*}$ \\
\hline \multicolumn{5}{|l|}{$\mathrm{Hb}(\mathrm{g} / \mathrm{dL})$, median (IQR) } \\
\hline Pre operation & $14.05(1.8)$ & $14.5(2.1)$ & $13.8(1.75)$ & 0.140 \\
\hline Post operation & $11.95(3.075)$ & $11.1(2.5)$ & $12.9(2.9)$ & $<0.001^{*}$ \\
\hline Female gender, $n(\%)$ & $16(16)$ & $6(12)$ & $10(20)$ & 0.275 \\
\hline \multicolumn{5}{|l|}{ Comorbidities, $n$} \\
\hline Hypertension & 71 & 33 & 38 & 0.271 \\
\hline Diabetes mellitus & 33 & 13 & 20 & 0.137 \\
\hline Renal dysfunction & 5 & 2 & 3 & 1.00 (exact $p$-value $)$ \\
\hline Ischaemic heart disease & 53 & 43 & 10 & $<0.001^{*}$ \\
\hline Congestive heart failure & 2 & 2 & 0 & 0.495 (exact $p$-value) \\
\hline Cerebrovascular disease/stroke & 9 & 4 & 5 & 1.00 (exact $p$-value) \\
\hline Number of grafts, $n$ patients & & & & $<0.001^{*}$ \\
\hline $1-2$ & 30 & 9 & 21 & \\
\hline 3 & 42 & 17 & 25 & \\
\hline $4-6$ & 28 & 24 & 4 & \\
\hline \multicolumn{5}{|l|}{ Preoperative medication, $n$} \\
\hline Warfarin & 6 & 2 & 4 & 0.678 (exact $p$-value) \\
\hline Aspirin & 67 & 38 & 29 & 0.556 \\
\hline Clopidogrel & 13 & 5 & 8 & 0.372 \\
\hline Previous coronary surgery, $n$ & & & & 0.585 \\
\hline None & 84 & 41 & 43 & \\
\hline CABG/coronary angioplasty/valve replacement/pacemaker & 16 & 9 & 7 & \\
\hline
\end{tabular}

Table 2. Generalised linear model result for RCCs*

\begin{tabular}{|c|c|c|c|}
\hline Independent variables (factors and covariates) & Wald $\chi^{2}$ & df & $p$-value \\
\hline Cerebrovascular disease or stroke & 2.977 & 1 & 0.084 \\
\hline Hospital & 18.330 & 1 & 0.000 \\
\hline Aspirin & 5.781 & 1 & 0.016 \\
\hline Previous cardiac surgery & 11.191 & 4 & 0.024 \\
\hline Number of grafts & 16.374 & 5 & 0.006 \\
\hline Clopidogrel & 3.162 & 1 & 0.075 \\
\hline Age & 9.052 & 1 & 0.003 \\
\hline Weight & 5.906 & 1 & 0.015 \\
\hline
\end{tabular}


$(p<0.05)$, weight $(p<0.05)$, aspirin use $(p<0.05)$ and previous cardiac surgery $(p<0.05)$. Use of clopidogrel $(p<0.1)$ and the prevalence of cerebrovascular disease $(p<0.1)$ were significant at the $\alpha$-level of 0.1 .

After transformation to an ordinal variable (Table 3) with fewer categories, the significant difference between hospitals was stronger $\left(\chi^{2}=27.35, \mathrm{df}=3, p<0.0001\right)$, with six variables emerging as having a significant influence on blood use by the hospitals (Table 4). The most significant factor in the use of RCCs was age $(p<0.001)$, followed by type of hospital $(p<0.01)$, weight $(p<0.05)$, number of grafts $(p<0.05)$ and aspirin use $(p<0.05)$. Use of warfarin $(p<0.1)$ was significant at the $\alpha$-level of 0.1 .

\section{Variables affecting FFP use}

Owing to very small frequencies in some categories, FFP was transformed into a binary variable indicating whether FFP was transfused or not. The cross-tabulation in Table 5 shows a significant difference in the number of times FFP was transfused between the two types of hospital $\left(\chi^{2}=13.28, \mathrm{df}=1, p<0.0001\right)$.

The results of the generalised linear model showed that the only significant factor in the number of times FFP was transfused was the hospital type $(p=0.002)$ (Table 6$)$.

Table 3. Frequency table of RCCs v. hospital type

\begin{tabular}{llllll}
\hline & \multicolumn{5}{c}{ Units of RCCs } \\
\cline { 2 - 5 } Hospital & $\mathbf{0}$ & $\mathbf{1 ~ - ~}$ & $\mathbf{3} \mathbf{- 4}$ & $\mathbf{2 5}$ & Total \\
\hline $\mathrm{P}, n$ patients & 22 & 14 & 3 & 11 & 50 \\
T, $n$ patients & 4 & 18 & 21 & 7 & 50 \\
Total, $N$ patients & 26 & 32 & 24 & 18 & 100 \\
RCCs $=$ red cell concentrates; $\mathrm{P}=$ private hospital; $\mathrm{T}$ = public hospital.
\end{tabular}

Table 4. Generalised linear model result for $\mathrm{RCCs}^{*}$

\begin{tabular}{llll}
\hline Source & Wald $\boldsymbol{\chi}^{\mathbf{2}}$ & df & $\boldsymbol{p}$-value \\
\hline Hospital & 10.077 & 1 & 0.002 \\
Warfarin & 3.571 & 1 & 0.059 \\
Aspirin & 4.884 & 1 & 0.027 \\
Number of grafts & 13.878 & 5 & 0.016 \\
Weight & 6.150 & 1 & 0.013 \\
Age & 11.257 & 1 & 0.001 \\
RCCs $=$ red cell concentrates. & & \\
*Dependent variable: RCCs transformed into fewer ordinal categories. Model (threshold): \\
$\begin{array}{l}\text { Hospital, Warfarin, Aspirin, Number of grafts, Weight, Age. Likelihood ratio } \chi^{2}=38.01, \\
p<0.001 .\end{array}$
\end{tabular}

Table 5. Number of times FFP transfused by hospital

\begin{tabular}{llll}
\hline Hospital & $\begin{array}{l}\text { No FFP } \\
\text { transfused }\end{array}$ & FFP transfused & Total \\
\hline P, $n$ patients & 48 & 2 & 50 \\
T, $n$ patients & 34 & 16 & 50 \\
Total, $N$ patients & 82 & 18 & 100 \\
FFP $=$ fresh-frozen plasma; $\mathrm{P}$ = private hospital; $\mathrm{T}$ = public hospital. &
\end{tabular}

Table 6. Generalised linear model result for FFP*

\begin{tabular}{llll}
\hline Source & Wald $\boldsymbol{\chi}^{2}$ & df & $\boldsymbol{p}$-value \\
\hline Intercept & 25.230 & 1 & $<0.001$ \\
Hospital & 9.591 & 1 & 0.002 \\
& & & \\
FFP $=$ fresh-frozen plasma. & \\
${ }^{*}$ Dependent variable: FFP. Model (intercept): Hospital. Likelihood ratio $\chi^{2}=14.80, p<0.001$.
\end{tabular}

\section{Variables influencing the transfusion of platelets}

Owing to a similar scarcity in cells, the platelet variable was transformed to a binary variable, indicating whether the patient received platelets or not, and the results demonstrated no significant difference between the two types of hospital in the number of times platelets were transfused $\left(\chi^{2}=0.22, \mathrm{df}=1, p>0.5\right)$ (Table 7).

The generalised linear model showed that two variables influenced the transfusion of the number of platelets, which excluded the type of hospital, confirming the $\chi^{2}$ result (Table 8 ).

\section{Summary}

Table 9 compares the factors influencing the number of units of RCCs used and the number of times FFP and platelets were transfused in the hospitals.

\section{Discussion}

In this retrospective study, blood use in CABG surgery at a tertiary referral university-affiliated public hospital and a private sector hospital was analysed and compared. The results showed that a significantly higher percentage of patients (92\%) at the public hospital received RCCs compared with the private hospital $(56 \%)(p<0.001)$. Similarly, there was a significant difference in the use of FFP, with $32 \%$ of patients at the public hospital receiving FFP compared with $4 \%$ at the private hospital $(p<0.01)$. However, there was no significant difference in the use of platelets ( $p>0.05)$.

In multivariate analyses, age, body mass, the number of grafts and use of aspirin and warfarin influenced the decision to administer RCCs. However, despite the private sector hospital having significantly older patients $(p<0.05)$ and performing significantly more grafts per

\begin{tabular}{llll}
\multicolumn{4}{c}{ Table 7. Number of times platelets transfused by hospital } \\
\hline Hospital & $\begin{array}{l}\text { No platelets } \\
\text { transfused }\end{array}$ & $\begin{array}{l}\text { Platelets } \\
\text { transfused }\end{array}$ & Total \\
\hline $\mathrm{P}, n$ patients & 37 & 13 & 50 \\
T, $n$ patients & 39 & 11 & 50 \\
Total, $N$ patients & 76 & 24 & 100 \\
P = private hospital; $\mathrm{T}$ = public hospital. & &
\end{tabular}

Table 8. Generalised linear model result for platelets*

\begin{tabular}{llll}
\hline Source & Wald $\boldsymbol{\chi}^{2}$ & $\mathbf{d f}$ & $\boldsymbol{p}$-value \\
\hline Gender & 4.037 & 1 & 0.045 \\
Clopidogrel & 3.938 & 1 & 0.047
\end{tabular}
${ }^{*}$ Dependent variable: Platelets. Model: Gender, Clopidogrel. Likelihood ratio $\chi^{2}=35.86$, $p<0.001$.

Table 9. Summary of factors influencing the use of RCCs, FFP and platelets

\begin{tabular}{llll}
\hline & RCCs & FFP & Platelets \\
\hline Age & $\checkmark$ & \\
Hospital & $\checkmark$ & $\checkmark$ & \\
Weight & $\checkmark$ & \\
Number of grafts & $\checkmark$ & \\
Aspirin & $\checkmark$ & \\
Warfarin & $\checkmark$ & $\checkmark$ \\
Gender & & $\checkmark$ \\
Clopidogrel & & \\
RCCs = red cell concentrates; FFP = fresh-frozen plasma. &
\end{tabular}


surgery ( $p<0.001)$, fewer RCCs were utilised. Previous researchers have reported that individuals with a lower body mass and size are more likely to receive transfusions, ${ }^{[17,18]}$ and this may provide an explanation for the increased use of RCCs in the public sector hospital, as this group of patients had significantly lower body weights $(p<0.05)$.

Most studies ${ }^{[7,19]}$ have shown an increase in blood use with age, but attribute this to the comorbidity profile and preoperative anaemia associated with ageing. ${ }^{[20,21]}$ In the present study, there was no significant difference in preoperative $\mathrm{Hb}$ concentrations between the two hospitals, and apart from ischaemia, no difference in the comorbidity profiles. This finding suggests that these factors did not influence the differences observed in the use of RCCs. Our findings further confirm earlier work showing that an increase in the number of grafts performed during cardiac surgery elevates complexity, risk and blood product utilisation. ${ }^{[22]}$ However, despite performing more grafts, the private hospital had a lower transfusion rate, suggesting that the additional grafts $(p<0.001)$ did not influence the differences observed between the two hospitals.

Although similar preoperative $\mathrm{Hb}$ levels were recorded, the private patients had significantly reduced postoperative $\mathrm{Hb}$ values, implying that the private hospital did not require a normal $\mathrm{Hb}$ prior to patient discharge. This policy is in line with a number of studies that have shown that it is not necessary to normalise $\mathrm{Hb}$ levels, ${ }^{[19,23]}$ provided there is no underlying haemopoietic pathology. Alternatively, a reason for the differences could be that the 'trigger' $\mathrm{Hb}$ level for RCC transfusion may be set at a higher level at the public hospital, while the differing patient demographics between the two facilities may also have influenced the results.

Administration of preoperative anticoagulants, such as aspirin, warfarin and clopidogrel, could cause bleeding postoperatively ${ }^{[24,25]}$ and may therefore be associated with increased use of RCCs. Our analysis has indeed demonstrated that taking warfarin and aspirin was associated with higher rates of RCC transfusions. However, as there was no significant difference between the numbers of patients taking these anticoagulants in the two hospitals, their use could not explain the higher utilisation of RCCs in the public hospital.

FFP is used to replace low levels of coagulation factors and to stop bleeding in patients receiving anticoagulant therapy. Unexpectedly, significantly more patients were given FFP in the public hospital compared with the private hospital $(p<0.0001)$, despite there being no difference in the use of anticoagulants and both the INR and aPTT results being within normal reference limits. Further analysis using a generalised linear model revealed that the only factor influencing this difference was the type of hospital. It must, however, be noted that the small numbers of patients receiving this blood product could have influenced the result, leading to bias, and further investigation is therefore required to confirm these findings.

The use of platelet concentrates was similar between the two hospitals, and multivariate analysis revealed that the only two variables influencing it were gender and the use of the drug clopidogrel. Female gender has previously been identified as being associated with increased use of blood products. ${ }^{[7,26]}$ This finding is, however, probably explained by smaller body size, which has been linked to intraoperative haemodilution, an increased risk of postoperative mortality and an increased number of blood transfusions. ${ }^{[27]}$ The drug clopidogrel, which was identified as a second variable, is successfully used in the prevention of thrombosis and acts by preventing platelet aggregation and inhibiting the binding of adenosine diphosphate to platelet receptors. ${ }^{[28]}$ Although useful in preventing thrombotic events, its anti-platelet properties could pose a risk of bleeding during surgery. Interestingly, although aspirin is also used to inhibit the function of platelets, and is widely used at both hospitals, it did not influence the decision to utilise platelet products.

Although a previous history of coronary interventions has been linked with an increase in blood product use, ${ }^{[29]}$ the present study was unable to demonstrate any significant difference owing to the low percentage of patients with a previous history. Additional analysis of the use of cardiopulmonary bypass machines was not relevant, as both hospitals made sole use of on-pump methods.

The use of intraoperative anticoagulants has also been shown to lead to increased blood use. ${ }^{[30]}$ Owing to the widespread use of heparin in this study and its half-dose reversal with protamine, we were not able to make any significant comparison between the two hospitals. Additionally, analysis of the antifibrinolytic medications aprotinin and tranexamic acid was irrelevant, because these products were not used by either hospital.

The efficacy of cell salvage, the process whereby blood loss during surgery is minimised by reusing it, has been well documented. ${ }^{[31]}$ Owing to the universal use of this procedure by both hospitals, a comparison of its effect on blood utilisation was not possible.

\section{Study limitations}

The results of this study are valuable in understanding blood use in an SA context, although the results may have some limitations. The audit was restricted to only two institutions in the Cape region, and is therefore not entirely representative of the Western Cape. For this reason, any general conclusions about blood usage practices in the public and private sector cannot be made and require the inclusion of more hospitals and centres. In addition, the study only focused on patients undergoing CABG surgery and excluded other forms of bypass and cardiac surgery, which are also large consumers of blood products. Although every effort was made to include all relevant information, the availability of a blood bank in the private hospital and the age and type of bypass equipment were omitted. As many private hospitals do not have blood banks on site, and are likely to have newer and more efficient equipment than public hospitals, these factors could have influenced the final results.

\section{Conclusions}

Despite the above limitations, the results of this study suggest that there is significant variation in the transfusion of RCCs and FFP between the two hospitals. The factors influencing this, as identified by multivariate analysis, include age, gender, body mass, the number of grafts performed per surgery, and the use of anticoagulant therapy. As blood transfusion remains a risk and is associated with worse outcomes in cardiac surgery, ${ }^{[32]}$ it is recommended that further investigation, including more hospitals, be conducted, and that regional blood management systems be established to standardise blood product use.

Declaration. The research for this study was done in fulfilment of the requirements for DW's MSc in Biomedical Sciences at the Cape Peninsula University of Technology.

Acknowledgements. None.

Author contributions. DW: conceptualisation, collection of data, analysis and writing of the first draft; CU: statistical analysis and approval of the final manuscript; AB: conceptualisation of project, supervision of student, analysis of results, intellectual input and approval of final manuscript; GMD: conceptualisation of project, supervision of student, intellectual input, approval of final manuscript and corresponding author. 
Funding. None.

Conflicts of interest. None.

1. Tempe DK, Khurana P. Optimal blood transfusion practice in cardiac surgery. J Cardiothorac Vasc Anesth 2018;32(6):2743-2745. https://doi.org/10.1053/j.jvca.2018.05.051

2. Scott BH. Blood transfusion in cardiac surgery: Is it appropriate? Ann Cardiac Anaesth 2007;10(2):108112. https://doi.org/10.4103/0971-9784.37935

3. Carson J, Terrin M, Noveck $\mathrm{H}$, et al. Liberal or restrictive transfusion in high-risk patients after hip surgery. N Engl J Med 2011;365(26):2453-2462. https://doi.org/10.1056/nejmoa1012452

4. Murphy GJ. Pike K, Rogers CA, et al. Liberal or restrictive transfusion after cardiac surgery. N Engl Med 2015;372:997-1008. https://doi.org/10.1056/nejmoal 403612

5. Camaj A, Zahuranec DB, Paone G, et al. Organisational contributors to the variation in red blood cell transfusion practices in cardiac surgery: Survey results from the state of Michigan. Anesth Analg 2017;125(3):975-980. https://doi.org/10.1213/ANE.0000000000002277

6. Rogers MAM, Blumberg N, Saint S, Langa KM, Nallamothu BK. Hospital variation in transfusion and infection after cardiac surgery: A cohort study. BMC Med 2009;7:37. https://doi.org/10.1186/1741-7015-7-37 7. Bennett-Guerrero E, Zhao Y, Ferguson TB, Peterson ED, Gammie, IS, Song HK. Variation in use of blood transfusion in coronary artery bypass graft surgery. JAMA 2010;304(14):1568-1575. https://doi. blood transfusion in coronary
org/10.1001/jama.2010.1406

8. Docherty AM, Walsh TS. Anemia and blood transfusion in the critically ill patient with cardiovascular disease. Crit Care 2017;21:61. https://doi.org/10.1186/s13054-017-1638-9

9. Du Pont-Thibodeau G, Harrington K, Lacroix J. Anemia and red blood cell transfusion in critically ill cardiac patients. Ann Intensive Care 2014;4:16. https://doi.org/10.1186/2110-5820-4-16

10. Horvath KA, Acker MA, Chang MS, et al. Blood transfusion and infection after cardiac surgery. Ann Thorac Surg 2013;95(6):2194-2201. https://doi.org/10.1016/j.athoracsur.2012.11.078

11. Phokontsi C, Muteba MK, Motshabi-Chakane P. Intraoperative usage of blood products in patients undergoing cardiac surgery on cardiopulmonary bypass. Wits J Clin Med 2019;1(2):75-80. https://hdl. handle.net/10520/EJC-173dfbc156 (accessed 11 October 2021).

12. Nadar K, Alphonsus CS, Hardy A. Blood transfusion related to procedure in adult patients undergoing cardiac surgery. S Afr J Anaesth Analg 2020;26(2):91-98. https://doi.org/10.36303/ undergoing cardiac surge

13. Young M. Private vs. public healthcare in South Africa. Honours thesis. Kalamazoo, Mich.: Western Michigan University, 2016. https://scholarworks.wmich.edu/honors_theses/2741 (accessed 11 Octobe 2021)

14. Simonoff JS. Analyzing Categorical Data. New York: Springer, 2003.

15. Agresti A. An Introduction to Categorical Data Analysis. 2nd ed. Hoboken, NJ: Wiley, 2007.

16. McCullagh P, Nelder JA. Generalised Linear Models. 2nd ed. London: Chapman \& Hall/CRC, 1989.

17. Aronow WS. Management of hypertension in patients undergoing surgery. Ann Transfus Med 2017;5(10):227. https://doi.org/10.21037/atm.2017.03.54

18. Denault A, Deschamps A, Tardif J, Lambert J, Perrault L. Pulmonary hypertension in cardiac surgery. Curr Cardiol Rev 2010;6(1):1-14. https://doi.org/10.2174/157340310790231671
19. Fakhry SM, Fata P. How low is too low? Cardiac risks with anaemia. Crit Care 2004;8:S11. https://doi. org/10.1186/cc2845

20. De Santo LS, Romano G, Mango E, et al. Age and blood transfusion: Relationship and prognostic De Santo LS, Romano G, Mango E, et al. Age and blood transfusion: Relationship and prognostic
implication in cardiac surgery. J Thorac Dis 2017;9(10):3719-3727. https://doi.org/10.21037/ jtd.2017.08.126

21. Patridge J, Harari D, Gossage J, Dhesi J. Anaemia in the older surgical patient: A review of prevalence, causes, implication and management. J R Soc Med 2013;106(7):269-277. https://doi. org/10.1177/0141076813479580

22. Lako S, Bilali S, Memishaj S, Daka A, et al. The impact of blood use on patients undergoing coronary artery bypass surgery: A prospective study. J Surg 2014;35:20-26. https://www.ncbi.nlm.nih.gov/pmc/ articles/PMC4321579/ (accessed 11 October 2021).

23. Edwards J, Morrison C, Tchatalbachev V, et al. Patient blood transfusion management: Discharge haemoglobin level as a surrogate marker for red blood cell utilisation appropriateness. Transfusion 2012;52(11):2445-2451. https://doi.org/10.1111/j.1537-2995.2012.03591

24. Elbadawi A, Saad M, Nairooz R. Aspirin use prior to coronary artery bypass grafting surgery: A systematic review. Curr Cardiol Rep 2017;19(2):18. https://doi.org/10.1007/s11886-017-0822-5

25. Biancari F, Myllyla M, Lepojarvi S, et al. Preoperative warfarin treatment and outcome of coronary artery bypass graft surgery. Ann Thorac Surg 2010;89(4):1139-1145. https://doi.org/10.1016/j. thoracsur.2008.12.072

26. Scott BH, Seifert FC, Glass PS, Grimson R. Blood use in patients undergoing coronary artery bypass surgery: Impact of cardiopulmonary bypass pump, hematocrit, gender, age, and body weight. Anesth Analg 2003;97(4):958-963. https://doi.org/10.1213/01.ane.0000081790.75298.d8

27. Ranucci M, Pazzaglia A, Bianchini C, Bozzetti G, Isgro G. Body size, gender and transfusions as determinants of outcome after coronary operations. Ann Thorac Surg 2008;85(2):481-487. https://doi. org/10.1016/j.athoracsur.2007.10.01

28. Maffrand J-P. The story of clopidogrel and its predecessor ticlopidine: Could these major antiplatelet and antithrombotic drugs be discovered and developed today? C R Chim 2012;15(8):737-743. https:// doi.org/10.1016/j.crci.2012.05.006

29. Kinaird T, Anderson R, Gallagher S, et al. Vascular access site and outcomes in 58,870 patients undergoing percutaneous coronary intervention with a previous history of coronary bypass surgery: Results from the British Cardiovascular Interventions Society national database. JACC Cardiovasc Interv 2018;11(5):482-492. https://doi.org/10.1016/j.jcin.2017.12.020

30. Rasoli S, Zeinah M, Athanasiou T, Kourliouros A. Optimal intraoperative anticoagulation strategy in patients undergoing off-pump coronary artery bypass. Interact Cardiovasc Thorac Surg 012.14(5):629-633 https://doi.org/10.1093/icyts/ivs003

31. Murphy GJ, Mumford AD, Rogers CA, et al. Diagnostic and therapeutic medical devices for safer blood management in cardiac surgery: Systematic reviews, observational studies and randomised controlled trials. Programme Grants Appl Res 2017;5(17). https://doi.org/10.3310/pgfar05170

32. Werner RS, Lipp C, Waldhans S, Kunzli A. Blood consumption in total arterial coronary artery bypass grafting. J Cardiothorac Surg 2020;15:23. https://doi.org/10.1186/s13019-020-1053-1

Accepted 11 August 2021. 